\title{
Violência sexual e segurança internacional: despolitização, descontextualização e colonização de uma agenda
}

Sexual Violence and International Security: Depoliticization, Decontextualization and Colonization of an Agenda

Violence sexuelle et sécurité internationale: dépolitisation, décontextualisation et colonisation d'un agenda

\section{Sílvia Roque}

\section{OpenEdition}

\section{Journals}

Edição electrónica

URL: http://journals.openedition.org/rccs/7811

DOI: $10.4000 /$ rccs. 7811

ISSN: 2182-7435

\section{Editora}

Centro de Estudos Sociais da Universidade de Coimbra

\section{Edição impressa}

Data de publição: 7 Novembro 2018

Paginação: 165-188

ISSN: 0254-1106

\section{Refêrencia eletrónica}

Sílvia Roque, «Violência sexual e segurança internacional: despolitização, descontextualização e colonização de uma agenda », Revista Crítica de Ciências Sociais [Online], Número especial | 2018, colocado online no dia 05 novembro 2018, criado a 02 maio 2019. URL : http:// journals.openedition.org/rccs/7811; DOI : 10.4000/rccs.7811 


\section{SÍLVIA ROQUE}

\section{Violência sexual e segurança internacional: despolitização, descontextualização e colonização de uma agenda*}

Este artigo analisa as Resoluções do Conselho de Segurança das Nações Unidas sobre violência sexual em contextos de conflito armado como um momento de securitização a partir do qual a violência sexual passa a ser vista como algo passível de punição, combate e prevenção na esfera internacional. Defende-se que, ao circunscreverem a violência sexual ao paradigma da segurança, as Resoluções acabam, no entanto, por colocar em causa o entendimento da mesma como uma questão sociopolítica mais vasta, ancorada em representações e ideologias de género e relacionada com dinâmicas de poder e de violência à escala global, comprometendo o seu potencial emancipatório.

Palavras-chave: Conselho de Segurança das Nações Unidas; feminismo; género; segurança; violência sexual.

\section{Introdução}

Apesar da recorrência da violência sexual durante as guerras e conflitos armados ter sido persistentemente denunciada por autoras e movimentos feministas durante o século xx (Brownmiller, 1975; Enloe, 1989), só no final dos anos 1990 esta viria a ser considerada como um problema a ser resolvido através da criação de normas e da implementação de políticas internacionais, materializada pela Agenda Mulheres, Paz e Segurança e por várias resoluções do Conselho de Segurança das Nações Unidas (CSNU). A violência sexual deixou, então, de ser vista como algo normal ou inevitável, dada a natureza da guerra e de uma masculinidade assente em pulsões

\footnotetext{
Este artigo foi desenvolvido com o apoio concedido pela Fundação para a Ciência e a Tecnologia no âmbito da Bolsa de pós-doutoramento com a referência SFRH/BPD/111638/2015.

Por outro lado, este artigo não existiria sem um processo de reflexão coletivo e as trocas permanentes com colegas e investigadoras a quem agradeço a inspiração e generosidade da partilha: Rita Santos, Tatiana Moura, Júlia Garraio, Joana Vasconcelos e Anastasia Oprea.
} 
pretensamente incontroláveis, e passou a ser vista como algo que pode e deve ser prevenido e combatido (Hirschauer, 2014).

A introdução deste assunto na agenda de um órgão como o CSNU recebeu naturalmente os maiores aplausos e contou com uma enorme mobilização de organizações e movimentos de mulheres e feministas por todo o mundo. No entanto, emergem cada vez mais críticas à forma como a construção político-discursiva da violência sexual, veiculada no âmbito desta Agenda e numa parte substancial do meio académico, acabou por circunscrevê-la a uma questão de segurança, colocando em causa o entendimento da mesma como uma questão sociopolítica mais vasta, ancorada em representações e ideologias de género e relacionada com dinâmicas de poder e de violência à escala global.

Este artigo insere-se nessa linha de pensamento e a preocupação central que o anima não é meramente teórica. Através da análise das Resoluções em causa, em diálogo com perspetivas críticas e casos ilustrativos, argumento que, na verdade, a securitização da violência sexual em contextos de conflitos armados na esfera internacional omite aspetos fundamentais da compreensão da violência sexual e das suas interseções com outras dimensões da violência, colocando limitações e, por vezes, pervertendo as práticas geradas no âmbito da Agenda Mulheres, Paz e Segurança.

Assim, começo por situar a análise no âmbito de uma tensão teórico-política entre um paradigma de segurança e um paradigma feminista e, em seguida, analiso três das implicações desta tensão no discurso gerado no âmbito da Agenda Mulheres, Paz e Conflito do CSNU. Em primeiro lugar, a despolitização da violência sexual. Em segundo lugar, a sua descontextualização. E, em terceiro lugar, a colonização de representações e práticas ativadas por estes discursos. Estes três processos têm, concluo, implicações na perpetuação da violência sexual, em contextos de guerra e de paz, já que, apesar da vasta onda de indignação e condenação internacionais da última década, não se vislumbra uma diminuição da mesma nem o fim da impunidade.

\section{Violência sexual: entre feminismo e segurança}

A violência sexual tem sido uma constante ao longo da história e constitui um caso paradigmático de um domínio no qual a culpabilização das vítimas e a impunidade assumem um lugar central na sua perpetuação, independentemente da sua condenação formal (Brownmiller, 1975; Bourke, 2007). Assim, a violência sexual foi e continua a ser, nas suas diversas formas, quer objeto de processos de normalização e aceitação social e política, quer de reflexão e condenação, em geometrias variáveis, de acordo com o período histórico, 
os diferentes contextos ideológicos, socioculturais e científicos e o peso de distintas perspetivas feministas na agenda política. Independentemente do sofrimento real das vítimas, as justificações e os significados atribuídos à violência sexual podem variar de forma considerável, mesmo quando nos concentramos apenas na sua forma mais comummente visibilizada: a violação. Tal como demonstra Joanna Bourke (2007), a ideologia dominante de género, raça e classe, travestida de ciência e de lei e transposta para o aparato médico-jurídico, determina a forma como as sociedades encaram a violação: negando-a, tornando-a invisível ou aceitável, estabelecendo hierarquias de vítimas e perpetradores ou punindo-a de acordo com essa hierarquia, muitas vezes, não com o objetivo de trazer justiça às vítimas, mas de proteger aquilo que é, na verdade, o que se considera ameaçado por essa violação: superioridade racial, nação, identidade, família, masculinidade.

Deste modo, nem sempre os avanços produzidos pela visibilização e condenação generalizadas da violência sexual têm motivos e efeitos lineares e positivos. As formas específicas de invisibilização como as de visibilização podem ter objetivos nem sempre coincidentes com os interesses das vítimas e da real diminuição da violência, como também podem constituir-se como formas de invisibilizar outros tipos de violência e outros caminhos para a combater. Tal como tem sucedido em diferentes contextos nacionais, também no contexto internacional é necessário ter em conta que não existem apenas potencialidades na utilização do poder coercivo dos governos e dos Estados para avançar numa agenda que garanta a segurança das mulheres (Bumiller, 2008: 2).

Uma das vias de maior repercussão e mobilização em torno do combate à violência sexual, no plano internacional, tem sido a Agenda Mulheres, Paz e Segurança enquadrada por várias Resoluções do CSNU, em colaboração com Estados e organizações da sociedade civil um pouco por todo o mundo. Neste âmbito, a Resolução 1325 (2000) do CSNU surgiu como instrumento precursor para reforçar a igualdade de género na área de segurança e da construção da paz e constitui um importante marco histórico ao conferir a visibilidade até então negada às mulheres em contextos de guerra e de pós-guerra, nomeadamente ao seu papel nos processos de mediação e construção da paz e a determinados tipos de violência, nomeadamente a violência sexual.

Esta Agenda vem responder a uma série de preocupações de organizações e movimentos de mulheres, assim como de ativistas e académicas feministas, nomeadamente no campo das políticas e dos estudos sobre paz e segurança. Em primeiro lugar, visibilizou sujeitos tradicionalmente nas margens da política internacional, pensando a guerra, a paz e a segurança 
a partir de experiências concretas de grupos invisibilizados e silenciados. A assunção desta Agenda vem confirmar que "o pessoal é político $e$ internacional", isto é, que as vidas quotidianas de mulheres e homens, as construções de masculinidade e feminilidade moldam a esfera internacional e vice-versa (Enloe, 1989: 195-200). No entanto, a circunscrição desta Agenda aos contextos de guerra, as conceções de género que lhe subjazem e os significados atribuídos à segurança revelam, na verdade, uma agenda limitada, ou reciclada (Cohn et al., 2004: 137), e não necessariamente complexa, transformadora e emancipadora (Shepherd, 2008; Santos et al., 2012).

Após a Resolução 1325 (CSNU, 2000), muitas outras foram aprovadas no âmbito desta Agenda. Neste artigo, centro-me sobretudo na Resolução 1820 (2008) (CSNU, 2008) e ainda naquelas que, dedicadas exclusivamente à violência sexual em conflitos armados, a complementam - as Resoluções 1888 (CSNU, 2009), 1960 (CSNU, 2010) e 2106 (CSNU, 2013).

QUADRO 1 - Resoluções do CSNU sobre violência sexual

\begin{tabular}{|c|c|c|c|}
\hline $\begin{array}{c}1820 \\
(2008)\end{array}$ & $\begin{array}{c}1888 \\
(2009)\end{array}$ & $\begin{array}{c}1960 \\
(2010)\end{array}$ & $\begin{array}{c}2106 \\
(2013)\end{array}$ \\
\hline $\begin{array}{l}\text { Centra-se na } \\
\text { violência sexual em } \\
\text { cenários de conflito } \\
\text { armado. } \\
\text { Reconhece pela } \\
\text { primeira vez que } \\
\text { a violência sexual } \\
\text { levada a cabo de } \\
\text { forma sistemática } \\
\text { em cenários de } \\
\text { conflito armado é } \\
\text { usada como arma } \\
\text { de guerra. }\end{array}$ & $\begin{array}{l}\text { Estabelece } \\
\text { medidas concretas } \\
\text { de liderança, } \\
\text { coordenação } \\
\text { e sistemas de } \\
\text { monitorização para } \\
\text { alcançar os objetivos } \\
\text { rapidamente. }\end{array}$ & $\begin{array}{l}\text { Coloca a ênfase } \\
\text { na impunidade em } \\
\text { casos de violência } \\
\text { sexual. }\end{array}$ & $\begin{array}{l}\text { Destaca a } \\
\text { importância de } \\
\text { grupos de mulheres } \\
\text { na sensibilização, } \\
\text { proteção e atenção } \\
\text { a sobreviventes de } \\
\text { violência sexual } \\
\text { (acesso a justiça } \\
\text { e reparações). } \\
\text { Refere pela primeira } \\
\text { vez o papel das } \\
\text { armas na violência } \\
\text { de género e } \\
\text { violência contra } \\
\text { mulheres e crianças }\end{array}$ \\
\hline
\end{tabular}

Fonte: Adaptado de Santos (2018).

Analiso aqui as limitações específicas destas Resoluções a partir de uma perspetiva assente no papel constitutivo dos discursos (Laclau e Mouffe, 1985), ou seja, nas formas como certos entendimentos, representações e mitologias são mobilizadas, intencionalmente ou não, por atores específicos, e como estes discursos constituem também práticas de guerra, de paz e de 
segurança (Jabri, 2007; Müller, 2008). Em relação a este último aspeto, parto ainda da conceptualização dos processos de securitização como processos a partir dos quais um determinado referente (assunto, grupo, objeto) é nomeado enquanto problema de segurança e se torna, por isso, uma ameaça, algo a ser tratado no domínio da exceção, enquanto ameaça existencial, por oposição ao da política normal, ativando e justificando uma série de respostas normativas e operacionais (Waever, 1995; Booth, 2007; Hirshauer, 2014).

Apesar da diversidade de perspetivas feministas sobre as causas, atores e impactos da violência sexual, em particular em conflitos armados (Leatherman, 2011: 11-20), existe uma problemática mais vasta subjacente a todas elas. Essa problemática diz respeito às tensões geradas pela conjugação de uma análise feminista da violência com uma análise baseada no paradigma da segurança. Esta conjugação manifesta-se de forma profundamente paradoxal. Por um lado, é necessário visibilizar as inseguranças e violências sexuadas de modo a preveni-las e combatê-las, isto é, securitizá-las. Por outro lado, uma vez bem-sucedida ao chamar a atenção dos decisores políticos, a securitização da violência sexual, como explico mais à frente, desencadeia também uma série de outros efeitos discursivos, políticos e práticos, alguns deles contraproducentes ou deturpadores dos objetivos de uma agenda de politização e emancipação, não só feminista, como também anticolonial e anticapitalista.

Neste artigo, concentro-me em três desses efeitos interligados entre si. Em primeiro lugar, um efeito de despolitização da violência sexual, transformada em problema estratégico-militar, burocrático e técnico-científico. Em segundo lugar, um efeito de descontextualização, ao ser retirada da análise mais vasta das relações de poder e violência com base no género. Em terceiro lugar, um efeito de reprodução de representações e práticas de colonização.

\section{A "violação como arma de guerra" e a despolitização da violência sexual} A Resolução 1820 (2008) surge no seguimento de vários marcos decisivos na visibilização e tentativa de punição da violência sexual em contextos de guerra. O primeiro destes marcos situa-se na guerra da Bósnia (tendo a violação sido integrada no julgamento e punição dos crimes de guerra), o segundo, no genocídio do Ruanda e o último na guerra na República Democrática do Congo. Através desta Resolução, a violência sexual foi elevada ao estatuto de assunto de segurança internacional, alvo da preocupação de Estados, agências civis e militares e organizações internacionais, os quais haviam historicamente ignorado as suas expressões e impactos 
em vários contextos de guerra, apesar de terem conhecimento sobre os mesmos (Harrington, 2010: 80-87), extravasando o âmbito das lutas e reivindicações feministas de longa data (Brownmiller, 1975).

Ao extravasar este âmbito, porém, a Resolução 1820 é demasiado circunscrita e problemática já que define que a violência sexual preocupante - ao ponto de se tornar passível de ativar políticas de exceção, que saem da esfera da política normal (Booth, 2007: 172) - é aquela que os Estados consideram como tendo potenciais impactos em termos de segurança nacional e internacional. Assim, a Resolução condena o uso da violação e de outras formas de violência sexual, lembrando que "podem constituir crimes de guerra, crimes contra a humanidade ou atos constitutivos de genocídio" e "apela aos Estados-membros para que cumpram com a sua obrigação de processar os indivíduos responsáveis por esses atos" (CSNU, 2008: 3 , ponto 4$),{ }_{1}^{1}$ considerando mesmo a utilização de sanções contra as partes dos conflitos que utilizem a violência sexual (ibidem: 3 , ponto 5), e define a violência sexual como tática de guerra deliberada e sistemática que coloca em causa a manutenção da paz e segurança internacionais:

Destaca que a violência sexual, quando se utiliza ou se faz utilizar como tática de guerra dirigida deliberadamente contra civis ou como parte de um ataque generalizado ou sistemático contra populações civis, pode agravar significativamente as situações de conflito armado e constituir impedimento ao restabelecimento da paz e da segurança internacionais, afirma nesse sentido que a adoção de medidas eficazes para prevenir os atos de violência sexual e reagir a eles pode contribuir consideravelmente para a manutenção da paz e da segurança internacionais. (CSNU, 2008: 2, ponto 1; itálicos no original, destaques da autora)

Isto significa, em primeiro lugar, uma limitação do reconhecimento da diversidade e da complexidade da associação entre violência sexual e militarização. Não é suficiente reconhecer que os tipos, as formas, os objetivos e os atores da violência sexual podem variar bastante conforme o contexto de guerra e os tipos de organização envolvidos (Cohen, 2013; Wood, 2014).

O que constituiria um passo realmente transformador, do ponto de vista da produção de significados e de políticas transformadoras, seria questionar tanto a noção de conflito armado como a noção de tática ou de estratégia de guerra subjacentes à Resolução, as quais são, na verdade, limitadas e limitativas. Desde logo, reconhecendo que, se a violência sexual, e especificamente

\footnotetext{
$\overline{1}$ Todas as traduções são da autora.
} 
a violação, ${ }^{2}$ pode ser militarizada, associada a grupos, ideologias e práticas militaristas, os seus objetivos e os espaços em que esta associação se expressa são mais vastos do que aqueles que a Resolução imagina e representa.

Cynthia Enloe, por exemplo, aponta pelo menos três formas de violação militarizada: a recreativa (quando os soldados violam sob o pretexto de necessidades biológicas, de diminuição do stress da guerra ou de uma recompensa pelos esforços de guerra, colecionando troféus); a violação praticada sob o pretexto da defesa da segurança nacional, como ato de tortura, dentro ou fora das fronteiras nacionais (os exemplos podem ir desde as práticas de tortura nas ditaduras latino-americanas nos anos 1980 até às práticas do exército dos Estados Unidos da América em Abu Ghraib, mais recentemente); e a violação sistemática em massa (com o objetivo de humilhar o inimigo, destruir o tecido social e espalhar o terror) (Enloe, 2000: 108-152), eventualmente constituindo também uma forma de genocídio. Já Donna Pankhurst aponta cinco explicações para a violação em contextos de conflito armado: a sua utilização como arma de guerra; como recompensa aos soldados; como resultado da quebra do controlo social; como consequência dos modelos de masculinidade; ou como expressão da relação frustração-agressão e do trauma masculino (Pankhurst, 2010: 152-156). Não pretendo aqui discutir cada uma destas explicações, mas antes salientar que, sendo indiscutível a utilização da violência sexual como arma de guerra, é também verdade que a circunscrição do debate sobre a mesma a este mantra globalizado pode ter alguns efeitos negativos sobre a compreensão da violência no sentido mais amplo (Santos et al., 2012; Eriksson Baaz e Stern, 2013; Davies e True, 2015; Meger, 2016).

A guerra é um momento de forte intensificação da violência organizada, mas é também um contexto de caos, imprevisibilidade e indefinição. Ao privilegiar uma análise da violência sexual centrada na tática ou na estratégia (enquanto ato premeditado, com objetivos em termos de mobilização de efetivos ou de condução da guerra, nomeadamente de limpeza étnica e genocídio), acaba por se invisibilizar, aglomerar ou ignorar uma série de práticas, cuja intencionalidade pode ser difícil de perceber, que resultam de complexas interações entre a violência sexual e de género em contextos de paz e de guerra ou entre violência estrutural, simbólica e interpessoal, as quais, por não constituírem exemplo do que se considera "arma de guerra" ou por não serem encaradas como uma ameaça à segurança internacional,

\footnotetext{
${ }^{2}$ A expressão mais óbvia da violência sexual é a violação, mas esta não se resume à mesma e é experienciada, muitas vezes, em associação com outras práticas, como atos de tortura, mutilação, gravidez forçada, aborto forçado, casamento forçado, escravatura sexual ou tráfico de seres humanos (Leatherman, 2011: 32).
} 
acabam por ser normalizadas. Ignora-se, assim, que a oposição conceptual e empírica entre guerra e paz é, em larga medida, artificial (Enloe, 1993; Scheper-Hughes e Bourgois, 2004: 1; Moura, 2010).

Assim, por um lado, a existência de uma guerra não indica que todas as práticas de violência sexual estejam diretamente ligadas ou sejam necessariamente produto dessa guerra ou ainda que sejam praticadas por soldados ou grupos em conflito e não por civis. Também, como explicam Maria Eriksson Baaz e Maria Stern, com base em entrevistas realizadas com soldados na República Democrática do Congo, as fronteiras entre violações motivadas pela guerra e violações motivadas por outros fatores, como a ordem dominante de género e sexualidade, são bastante porosas: ao analisarem os discursos que os soldados utilizam para justificar as violações, encontram uma distinção, proposta pelos mesmos, entre violações causadas pelo desejo sexual incontrolável, as quais seriam ética e socialmente defensáveis, e violações de maldade, provocadas pela raiva, menos defensáveis, mas, ainda assim, compreensíveis, do seu ponto de vista (Eriksson Baaz e Stern, 2009: 497). Além disso, se, por vezes, a estratégia militar pode ditar a prática da violência sexual, outras vezes, ela é também uma forma de controlo da mesma, tornando-a simultaneamente pública e privada, civil e militar (Zipfel, 2013:35).

Por outro lado, as Resoluções do CSNU ignoram extensões da violência militarizada em contextos, instituições e grupos onde a violência sexual constitui uma das possíveis lógicas de agressão externa, mas também internamente uma forma de criação de uma identidade coletiva, de uma afirmação de poder ou de uma atuação normalizada pelos modelos dominantes de género. Exemplos disso podem ser encontrados tanto na atuação de grupos considerados ilegítimos, como os gangues (Roque, 2012), como dentro de grupos e instituições consideradas legítimas, como os exércitos ou as escolas militares (Broadbent, 2011; Lecaplain e Moran, 2018), espaços permeados por elevados níveis de violência sexual e outras práticas discriminatórias (Via, 2010: 45). Em ambos os casos, a violência sexual pode ser usada como uma forma normalizada de disciplinar sujeitos vistos como transgressores (mulheres ou homens) e de afirmar uma posição de poder. Assim, a violência sexual não se trata de um problema apenas de indivíduos não disciplinados ou descontrolados que afeta vítimas fora dessas instituições ou grupos, ela exerce-se dentro das mesmas tanto como expressão de associação à militarização e de associação a práticas de guerra, como enquanto expressão de relações sociais de género desiguais mais vastas, como argumento na próxima secção deste artigo.

Em segundo lugar, um entendimento da violência sexual limitado à sua utilização como arma de guerra e como ameaça à segurança internacional 
e à manutenção da paz, sem atender aos aspetos mais vastos da produção da violência de género, estabelece uma hierarquia de relevância e de gravidade dos atos de violência segundo o contexto, de guerra ou de paz, o que tem consequências no entendimento dos sujeitos a proteger. Como ativistas e autoras feministas vêm reclamando pelo menos desde os anos 1970, uma parte considerável da violência sexual acontece no foro doméstico, íntimo ou de proximidade e em tempos de paz. No entanto, esta violência não é considerada como uma ameaça à segurança internacional ou como obedecendo a motivações táticas ou estratégicas. Ora, a violência sexual em contexto de guerra não deveria invisibilizar ou secundarizar a violência quotidiana experienciada por mulheres, e também por homens, em contextos patriarcais e heterossexistas.

Neste entendimento, expresso nas Resoluções, dos usos e dos impactos da violência sexual, continuam a ser o Estado, o grupo, a região ou a paz global os referentes últimos da segurança e não as vítimas da violência (Meger, 2016: 151). Na verdade, se a securitização da violência sexual em conflitos armados foi bem-sucedida ao trazer para a agenda internacional algumas das dimensões de género da segurança, os discursos de segurança ativados são sempre também sobre dimensões que, muitas vezes, se sobrepõem ou instrumentalizam a dimensão de género, como o Estado, a ideologia, a nação, a etnia ou a cultura (Hansen, 2001: 55; Chiwengo, 2008; Garraio, 2012, 2013).

A edificação de um aparato discursivo e operativo de segurança internacional em torno da violência sexual vem, assim, criar processos de securitização institucionalizada (Hansen, 2012: 532) ou de securitização permanente (Hirshauer, 2014: 7) e reforçar ainda mais o imaginário da guerra como algo normal, campo da violência legítima, embora suscetível de ser controlada e circunscrita através de normas que delimitam a violência aceitável (Zipfel, 2013:37).

Consequentemente, o aparato das Resoluções acaba por delimitar a violência sexual a uma questão a ser tratada, em primeiro lugar e fundamentalmente, por militares. As medidas propostas centram-se essencialmente no reforço da disciplina (CSNU, 2008: 3, ponto 3) e na inclusão da dimensão de género nos programas de Desmobilização, Desarmamento e Reintegração e de Reforma do Setor de Segurança (CSNU, 2013: 4-5, ponto 16). Em segundo lugar, deve ser tratada por técnicos, especialistas e sistemas de justiça e de saúde, instando, em particular, ao apoio aos "sistemas judiciais e de saúde, e das redes locais da sociedade civil para que prestem assistência sustentável às vítimas da violência sexual" (CSNU, 2008: 4, ponto 13); apelando a reformas legislativas e à elaboração de procedimentos judiciais para proteção de 
vítimas e testemunhas (CSNU, 2013: 5, ponto 16); e estabelecendo como prioridade de atendimento, tratamento e apoio às vítimas da guerra a intervenção junto de sobreviventes da violência sexual, aos quais é ainda acrescido o fardo da infeção do HIV/SIDA (ibidem: 5 , pontos 19 e 20).

Segundo Carol Harrington, a progressiva hegemonia do paradigma do trauma individual, enquanto justificação para um posicionamento de condenação e de resposta à violência sexual, acabou por transformar os contextos de pós-guerra em "zonas de emergência de saúde mental" (Harrington, 2010: 126). A tendência para assumir uma posição de combate à violência sexual com base no grau de sofrimento causado, em lugar de um posicionamento ético de partida (ibidem: 118), contribuiu para a medicalização e individualização das respostas à violência sexual, centradas nas vítimas diretas da mesma e ignorando, na maioria das vezes, a extensão social da violência, assim como os seus perpetradores. Neste contexto, a "intervenção política internacional é vista como assistência terapêutica dirigida a transformar as vítimas em sobreviventes" e "os programas de manutenção da paz e de democratização" tornam-se cada vez mais intrusivos na transformação social pretendida, com a ambição de reestruturar a "psicologia individual e as relações pessoais" (ibidem: 121).

Neste sentido, e em articulação com os efeitos que analiso em seguida, a despolitização da violência sexual parece constituir um efeito de congruência com a despolitização, geral, da intervenção internacional. ${ }^{3}$

\section{Descontextualização: a violência sexual sem género?}

As Resoluções aqui analisadas ensaiam discursos e representações de género um pouco diferentes daquelas expressas na Resolução 1325 (2000). Enquanto nesta primeira Resolução, apesar da recorrente utilização da expressão "género", as "mulheres e crianças", as "mulheres e raparigas" são identificadas como os alvos, estando ausentes os homens, assim como a dimensão relacional do género (Santos et al., 2012: 171), na Resolução 1820 (2008), a linguagem utilizada altera-se um pouco.

Esta alteração vai no sentido de incluir os homens, sem que, no entanto, sejam nomeados enquanto tal. Assim, na fórmula recorrente ao longo da Resolução 1820, bem como das subsequentes, refere-se a violência "contra populações civis", observa-se que "os civis constituem a grande maioria das pessoas afetadas negativamente pelos conflitos armados", acrescentando-se, sempre, "em particular mulheres e raparigas", destacando "que as mulheres

\footnotetext{
${ }^{3}$ Para uma análise sobre o processo de despolitização da intervenção internacional, ver, por exemplo, Ferguson (1990) ou Duffield (2001, 2010).
} 
e as raparigas são especialmente objeto de atos de violência sexual" (CSNU, 2008: 1). Só na Resolução 2106 (2013) surgem especificamente nomeados uma vez os "homens e rapazes" como vítimas de violência sexual direta e indireta - enquanto testemunhas forçadas e traumatizadas (CSNU, 2013: 1-2) -, continuando o resto da Resolução a referir-se às vítimas da violência como "mulheres e raparigas". No conjunto das Resoluções, a menção ao género, enquanto sistema amplo e relacional de práticas e representações, tratado no âmbito das políticas normais, surge apenas uma vez:

Destaca a importante função que a Comissão de Consolidação da Paz pode desempenhar ao incluir no seu aconselhamento e nas suas recomendações sobre as estratégias de consolidação da paz pós-conflito, sempre que possível, maneiras de abordar a violência sexual perpetrada durante um conflito armado ou posteriormente, e ao assegurar a consulta e a representação efetiva das mulheres da sociedade civil nas suas configurações específicas de cada país, como parte do seu enfoque mais amplo das questões de género. (CSNU, 2008: 4, ponto 11; itálico no original, destaques da autora)

Ora, parece tarefa inglória tentar combater a violência sexual sem questionar o papel das construções sociais de género na sua reprodução. No entanto, as Resoluções limitam-se a identificar vítimas mais ou menos prováveis e a apontar soluções militares, técnicas e científicas que não questionam as razões pelas quais as violações e a violência sexual são consideradas armas de guerra eficazes. Não há qualquer referência ao substrato ideológico, normativo e estratégico que alimenta a conceção da violência sexual como estratégia eficaz de controlo e inflição de sofrimento ao inimigo em tempos de guerra, mas também em tempos de paz. Como também não há qualquer referência às estruturas sociais que determinam relações de poder fundadas na desigualdade de género, em determinadas perceções de masculinidade e feminilidade, em conjugação com outras lentes como a idade, a raça, a etnia, a orientação sexual ou a classe social, dimensões nunca referidas nas Resoluções.

Assim, apesar de referir brevemente a existência de "mitos que alimentam a violência sexual" (CSNU, 2008: 3), em nenhum momento a Resolução 1820, ou as seguintes, explicita quais as ideologias e práticas de poder que alimentam, por sua vez, estes mitos, preferindo concentrar-se na

aplicação de medidas apropriadas de disciplina militar, [no] cumprimento do princípio da responsabilidade do comando, [na] formação das tropas para a proibição categórica de todas as formas de violência sexual contra civis, [...] [ou na] verificação 
de antecedentes das forças armadas e de segurança para considerar o seu histórico de violações e outras formas de violência sexual. (CSNU, 2008: 3, ponto 3)

As medidas centram-se, assim, numa ideia de hierarquia e princípios militares que contrariariam as pulsões ou a falta de conhecimento sobre as regras da guerra, e não na reversão de princípios estruturantes das próprias instituições bélicas e da violência nas sociedades e nas relações internacionais.

Em primeiro lugar, seria preciso ter em conta a forma como ordens de género, normas e instituições patriarcais relacionadas com o casamento, a paternidade ou a sexualidade "que definem as mulheres como inferiores ou como propriedade [e] atribuem significados à violação, não apenas do corpo feminino, mas também de normas sociais enraizadas e relacionadas com a identidade nacional e a segurança”, têm impactos na perpetração da violência sexual, em contextos de guerra e de paz (Mackenzie, 2010: 203). Importa recuperar o pensamento feminista que explica como determinados estereótipos reforçam dinâmicas de violência direta ou indiretamente, como o mito do homem-protetor versus a mulher-protegida, assente numa divisão de atributos como força versus fragilidade, atividade versus passividade, o qual contribui para justificar táticas que pretendem ferir o inimigo ou construir as nações através da ocupação e humilhação dos corpos de mulheres (e de homens) de modo a demonstrar superioridade (Elshtain,1987; Mackinnon, 1994). Estes estereótipos são alimentados e reforçados na própria constituição dos exércitos, regulares ou irregulares, mesmo quando existe uma aparência de feminização dos mesmos (Whitworth, 2005; Carreiras, 2010: 474-479). Significa ainda reconhecer como as constantes associações entre "mulheres-sedutoras-fonte de problemas" e entre "homens-seduzidos-sem capacidade de controlar os seus instintos" estão na base dos diversos "mitos sobre a violação" (Bourke, 2007: 21-49) que circulam em discursos incorporados nas práticas de instituições e atores de segurança.

Em segundo lugar, importa trazer para o centro desta discussão algo que é permanentemente ocultado das Resoluções e da discussão centrada na estratégia de guerra: os homens e as masculinidades. Se os agressores sexuais são esmagadoramente do sexo masculino, isto não significa que os homens estejam biológica e inevitavelmente programados para a exercer. Colocar os homens e as masculinidades no centro da equação significa adotar uma análise não-essencialista baseada na construção social e política das masculinidades e na sua relação com a violência, incluindo a violência sexual, com a guerra e com diferentes formas de militarização. 
Assim, continua a ser importante perceber como construções de masculinidades hegemónicas, baseadas na heterossexualidade compulsiva, na repressão das emoções, na negação da fragilidade e na normalização da agressividade contribuem para o exercício da violência, mas constituem também elas próprias formas de exercício da violência. Os homens, tal como as mulheres, encontram-se permanentemente no cruzamento de várias lógicas de mitificação e expetativas, controlo e reprodução social assim como de resistência. Logo, tanto há lugar para a frustração face ao incumprimento de ideias e modelos de masculinidade e à perda de privilégios (Kimmel, 2005), como há lugar para a diversidade, a divergência e a subversão de modelos, experiências e aspirações.

Neste sentido, mais do que tentar estabelecer relações de causa-efeito entre masculinidade e violência, é necessário perceber como as construções de masculinidade são instrumentais e necessárias para justificar ou tornar inteligível a guerra (Hutchings, 2008). Assim a investigação feminista tem realçado como a guerra e o militarismo são suportados pela tarefa permanente de criação de masculinidades e feminilidades hegemónicas e subalternas que dão sentido à sua perpetuação, apesar das mudanças nas práticas concretas da estratégia militar (Enloe, 1989, 2000; Hutchings, 2008).

Esta associação profunda entre masculinidade e guerra traduz-se tanto na visibilidade não assumida da predominância dos homens-como-agressores como também na quase invisibilidade dos homens-como-vítimas e na total invisibilidade das mulheres-como-perpetradoras (Munn, 2008; Zipfel, 2013) nas Resoluções. De facto, o potencial de exercício da violência sexual partilhado por homens e mulheres, ainda que de diferentes formas, tem sido descuidado da análise e dos discursos internacionais sobre violência, inclusivamente por uma parte dos discursos feministas (Roque, 2012). No entanto, como bem aponta Gaby Zipfel (2013), recorrendo a vários casos históricos que incluem vítimas do sexo masculino e em que há tanto perpetradoras como perpetradores, existe um potencial de violência em todos e todas, relacionado, entre outras coisas, com a relação entre violência, sexualidade e desejo, transposta em fascínio pela - e prazer com a - violência, o qual raramente é avançado, sobretudo se nos centrarmos apenas na violação e não nas várias formas de violência sexual.

Isto leva ainda a refletir sobre a insuficiência de uma análise isolada e abstrata das construções de género que alimentam a guerra e a violência sexual, sendo necessário analisar dimensões que são totalmente ocultadas das Resoluções em causa e que dizem respeito às extensões da violência sexual nas diversas expressões globais do poder e da violência. 


\section{Colonização: extensões globais de violência e de desejo}

As Resoluções aqui analisadas estão marcadas por um silêncio ensurdecedor: o do imaginário racializado e das práticas de colonização subjacentes em muitos dos discursos sobre violência sexual em conflitos armados. Tal como naturalizam a guerra, as Resoluções naturalizam outras formas de violência e dominação que operam à escala global, como a ordem capitalista e neoliberal, o racismo ou novas e velhas formas de colonialismo (Enloe, 2000; Agathangelou e Ling, 2004; Nayak e Suchland, 2006).

Assim, sem nunca o fazer diretamente, as Resoluções acabam por localizar geográfica, cultural e racialmente a violência sexual, nas margens do sistema internacional e no contexto de hegemonia do pensamento e produção académica sobre a transformação da guerra, fazendo coincidir, de forma artificial, a violência sexual em conflitos armados com as "novas guerras".

Estas "novas guerras" teriam uma natureza predominantemente intraestatal, assentes em dinâmicas de privatização da violência e de erosão da soberania dos Estados; seriam mais violentas e dirigidas sobretudo contra a população civil (Kaldor, 2001), e daí a eventual maior utilização da violência sexual como arma de guerra. Além disso, estas guerras seriam motivadas por razões identitárias, culturais e religiosas, e diluiriam as distinções modernas entre política e economia, público e privado, com a multiplicação de atores internacionais e transnacionais implicados; ao mesmo tempo, seriam acompanhadas por uma crescente informalidade e criminalização da economia que as sustenta (ibidem). É na suposta novidade destas guerras que radica a maior parte das críticas: essa assunção de novidade não só revela um viés extremamente eurocêntrico (Chan, 2011) e historicamente pouco denso (Kalyvas, 2001) como torna excecionais traços que fazem parte recorrente das guerras (Kalyvas, 2001; Duffield e Waddell, 2006), como a violência sexual, até então ignorada, mas nem por isso inexistente (Harrington, 2010). Assim, a distinção entre "novas guerras", guerras tidas como "criminosas, despolitizadas, privadas, predatórias" onde o uso da violência é "sem sentido e gratuito", e "velhas guerras civis"/internas, consideradas "disciplinadas", "ideológicas, políticas, coletivas, e até nobres", em busca de "mudanças sociais" (Kalyvas, 2001: 100-102), não é comprovada, nomeadamente no sentido de serem supostamente mais violentas e afetarem mais a população civil (Kalyvas, 2001: 114; Chan, 2011).

Além da questão da novidade, interessa destacar que a representação das causas das guerras contribui definitivamente para diferenciar as "novas guerras" das periferias das velhas guerras centrais através de um critério de legitimidade, usado, por exemplo, para analisar as guerras que sucederam na década de 1990 na África Ocidental. Estas são guerras que alguns tratarão 
de classificar como pré-modernas, bárbaras e irracionais e resultado da cultura ou serão ainda reduzidas ao tema da "ganância" dos líderes e da pilhagem (Collier e Hoeffler, 1998, 2004). Estas representações conduziram ao enraizamento de uma divisão do mundo entre zonas propensas à violência (Das e Kleinamn, 2000) e zonas de paz; passando o Sul global a ser visto como fonte de "instabilidade internacional", "de conflitos, atividade criminosa e terrorismo" e simultaneamente o "subdesenvolvimento" visto como "perigoso" (Duffield, 2001: 2). Perante a frequente associação entre o final da Guerra Fria e a expansão de uma zona de paz liberal cujos limites seriam atribuídos ao iliberalismo dos atores e às configurações políticas das zonas de guerra, saiu reforçada a associação entre as periferias e a violência, oscilando a representação desta associação entre a "hipervisibilização ameaçadora" (da violência direta) e a "invisibilização negadora" (das violências indiretas e da reprodução da violência) (Pureza, 2013: 203). Além do aparato das Resoluções, esta tendência de representação é particularmente notável nas caraterizações da República Democrática do Congo como a "capital mundial da violação", presentes nos mais variados discursos mediáticos, políticos e académicos, um dos elementos de reforço da irracionalidade, selvajaria e absoluta diferença desta guerra e desta cultura (Eriksson Baaz e Stern, 2013; Oprea, 2013). Esta localização subtil pode ver-se na formulação que:

Encoraja os líderes ao nível nacional e local, incluindo os líderes tradicionais onde eles existem e os líderes religiosos, a desempenhar um papel mais ativo na sensibilização das comunidades [...] para evitar a marginalização e a estigmatização das vítimas. (CSNU, 2009: 5-6, ponto 15; itálico no original, destaques da autora)

Indiretamente, a violência sexual e os seus efeitos traumáticos são vistos como resultado da tradição, tantas vezes utilizada como sinónimo de cultura e, por sua vez, como sinónimo de atraso, característica apenas de algumas partes do mundo. Esta associação não é exclusiva a África. Lene Hansen analisa, por exemplo, as fórmulas subjacentes às explicações e representações sobre os acontecimentos na Bósnia e, em pelo menos duas delas, a violação é justificada com recurso à sua associação a uma cultura dos Balcãs, particularmente violenta e patriarcal (Hansen, 2001). Este tipo de associação cultural circula extensamente e pode ser encontrado nos mais variados exemplos, nomeadamente na construção orientalista de uma suposta "mentalidade islâmica" ou de um "caráter árabe", reproduzido, por exemplo, para justificar a tortura em Abu Ghraib (Nusair, 2008: 181) ou as agressões sexuais imputadas a refugiados na noite de Ano Novo em Colónia (Alemanha), em 2016. 
Tal como já havia demonstrado Angela Davis (1983), a propósito da construção do mito do "violador negro" nos Estados Unidos da América, há sempre suspeitos mais suspeitos e mais ameaçadores do que outros. No contexto de securitização da violência sexual, várias fórmulas racializadas e coloniais de representação trasladam-se para a cena pós-colonial global (Nusair, 2008; Pratt, 2013) e menorizam determinadas formas e atores da violência, através de uma narrativa recorrente que remete a violência sexual ora para o domínio da exceção e da barbárie, ora para a sua normalização.

As duas tendências baseiam-se numa suposta especificidade e inferioridade cultural, a qual justifica a maior ou menor gravidade dos acontecimentos, dependendo dos propósitos discursivos e do tipo de intervenção internacional que esta narrativa ativa. Quando o propósito é justificar uma intervenção militar, as violações e outras violências contra as mulheres constituem graves violações dos direitos humanos, mesmo que para isso tenham que ser inventados números, como sucedeu nos casos do Iraque e do Kosovo (Harrington, 2010: 137). Já quando se trata da violência sexual praticada por soldados das Nações Unidas ou por outros trabalhadores do complexo humanitário e securitário, os discursos e as penas tornam-se mais brandas. Apesar da menção constante em todas as Resoluções à política de tolerância zero, e do reconhecimento implícito da violência praticada por funcionários mandatados pelas Nações Unidas, as violações cometidas pelas partes beligerantes são consideradas um crime de guerra, enquanto as outras são consideradas um problema de "capacitação", 4 de "conscientização" ou de "responsabilização" individual através dos Estados-membros (Pratt, 2013; Defeis, 2008: 192), reforçando, assim, a separação entre crimes de guerra e crimes de paz.

Tal como algumas análises sobre a Resolução 1325 têm demonstrado, o aparato de securitização aciona um imaginário que define como duplas vítimas,

\footnotetext{
${ }^{4}$ No ponto 6 da Resolução 1820, pede-se "ao Secretário-Geral que, em consulta com o Conselho de Segurança, o Comité Especial para as Operações de Manutenção da Paz e o seu Grupo de Trabalho e os Estados relevantes, sempre que pertinente, elabore e execute programas apropriados de formação para todo o pessoal bumanitário e de manutenção da paz destacado pelas Nações Unidas no contexto de missões estabelecidas pelo Conselho para os ajudar a uma melhor prevenção, identificação e resposta à violência sexual e a outras formas de violência contra civis" (CSNU, 2008: 3; itálicos da autora).

${ }^{5}$ No ponto 7 da Resolução 1820, pede-se "ao Secretário-Geral que prossiga e intensifique os esforços para aplicar a política de tolerância zero da exploração e do abuso sexuais nas operações de manutenção da paz das Nações Unidas, e insta [-se] os países contribuintes de tropas e polícias a adotarem medidas preventivas apropriadas, inclusive mediante a formação de sensibilização antes do destacamento e no teatro de operações, bem como outras medidas para garantir a responsabilização plena nos casos de conduta desse tipo que envolvam o seu pessoal" (CSNU, 2008: 3 ; itálico no original, destaques da autora).
} 
dos homens e das especificidades culturais e sociedades mais patriarcais, as mulheres racializadas e subalternizadas; como agressores e ameaças à segurança internacional, os homens racializados e subalternizados; e, como protetores e defensores, a comunidade internacional incorporada por homens e mulheres não-racializados e não-subalternizados (Shepherd, 2007; Santos et al., 2012; Pratt, 2013).

As Resoluções sobre violência sexual não fogem desta norma, pelo contrário, reforçam todas as dimensões e aprofundam o imaginário da comunidade internacional como salvadora, em particular, através do constante apelo à feminização das missões militares de manutenção da paz, encorajando "os países contribuintes [...] a, sempre que possível, destacar uma percentagem mais elevada de mulheres para as forças policiais ou de manutenção da paz" (CSNU, 2008: 3, ponto 8). Esta política de feminização transforma as mulheres que fazem parte das missões de paz em responsáveis pela transformação das masculinidades e das instituições, baseando-se numa perspetiva de sobre-humanização das mulheres, vistas como super-heroínas, necessariamente pacíficas (Shepherd, 2011) ou como figuras maternas e moralizadoras dos homens (Simi , 2010), ignorando que as próprias não só muitas vezes são vítimas de violência no seu contexto de trabalho, sob as mais variadas formas, como muitas vezes ignoram, são indiferentes ou não têm capacidade para deter ou denunciar práticas de violência. Na verdade, parecem existir poucas provas de que o facto de haver mais mulheres nas missões tenha diminuído as ocorrências de violência sexual nas missões de paz ou noutros contextos humanitários (Simi , 2010).

Ao mesmo tempo, é ainda importante realçar que este aparato securitário é pensado, produzido e implementado no contexto de um sistema capitalista, neoliberal e permeado pela reprodução de práticas coloniais, incluindo o racismo. Por isso mesmo, as formas como estas estruturas e práticas de poder e violência atuam, tanto na guerra como na paz, em relação com as diversas formas de violência sexual, são invisibilizadas através dos aparatos político-discursivos das Resoluções, através dos quais se estabelecem e normalizam, por um lado, hierarquias estruturais de desejo, as quais na verdade transnacionalizam a violência (Agathangelou e Ling, 2004: 519) sob a capa de segurança, proteção ou comercialização de trabalho sexual; e, por outro lado, alimentam também lógicas de fetichização e consumo das pessoas e da própria violência sexual, transformada em produto e em modo de obtenção de recursos, tanto por quem trabalha sobre a mesma, para ajudar e proteger as vítimas, como por parte de quem necessita de se apresentar como vítima para aceder aos limitados recursos da ajuda internacional (Eriksson Baaz e Stern, 2013: 99-102; Meger, 2016). 
Estas omissões constituem-se, em si mesmas, como expressões da violência do internacional. O internacional que, apesar de uma roupagem liberal e humanitária, reproduz lógicas de poder, representação e atuação reminiscentes das lógicas coloniais civilizadoras. Neste sentido, cabe realçar que a securitização da violência sexual em contexto de conflito armado acaba também por revelar o intervencionismo como expressão da supremacia do internacional sobre o local. O "internacional" é imaginado e construído simbólica e discursivamente como o espaço da resolução dos conflitos e da paz, enquanto o "local" seria o espaço do conflito e da violência. Neste contexto, o internacional torna-se a expressão de um novo espaço de expressão do colonial, tanto do ponto de vista material como simbólico: neocolonialismo e colonialidade do poder e do saber reforçam-se quer através da conquista territorial e militar, quer dos discursos justificativos das intervenções (Jabri, 2013: 8), sejam elas militares ou civis.

\section{Conclusões}

Quem protege quem de quem ou de quê e como? Pode resumir-se, assim, a questão que este artigo problematiza a partir da análise dos discursos sobre violência sexual e segurança internacional avançados pelas Resoluções do Conselho de Segurança das Nações Unidas. Uma pergunta que várias feministas têm vindo a colocar no âmbito dos estudos políticos e de segurança. Ao ensaiar uma resposta, uma perspetiva feminista é, por isso, também inevitável.

Assim, argumento que a introdução de novos sujeitos a proteger no domínio da segurança internacional promovida pelas Resoluções é não só insuficiente como também enviesa o olhar sobre quem ou o quê deve ser tido em conta para compreender e responder de forma complexa e efetiva à violência sexual como fenómeno tão global como localizado. Desde logo, é preciso olhar para a violência sexual para lá do seu entendimento restrito como estratégia de guerra, evitando a sua despolitização e transformação num assunto de segurança - militar, técnico, científico e burocrático, e para lá dos contextos tradicionalmente vistos como guerra. E, neste sentido, é ainda necessário recontextualizar a violência sexual no âmbito em que sempre foi denunciada e contestada, o da análise e reivindicação feminista, não excluindo a análise de género, trazendo as masculinidades para o centro da discussão e recuperando a interligação entre as violências da guerra e as violências da paz. Além disso, é preciso repensar quem é agente de proteção e de ameaça, descentrando o olhar em relação aos Outros nas margens e dirigindo-o para o centro do sistema internacional e para a forma como este produz discursos que o invisibilizam enquanto produtor de inúmeras formas de dominação, exclusão e violência. 
A violência sexual só pode ser entendida e combatida se encarada como expressão de um continuum de violências de género, mas também de violências mais amplas e suas extensões globais, das quais faz parte a lógica de intervenção internacional dominante que procura fundamentalmente proteger o statu quo através da reprodução ou atualização de formas de controlo baseadas em entendimentos restritos de segurança, de género e de violência.

\section{Revisto por Victor Ferreira}

\section{Referências bibliográficas}

Agathangelou, Anna M.; Ling, L.H.M (2004) "Power, Borders, Security, Wealth: Lessons of Violence and Desire from September 11", International Studies Quarterly, 48(3), 517-538. DOI: 10.1111/j.0020-8833.2004.00313.x.

Booth, Ken (2007), Theory of World Security. Cambridge: Cambridge University Press. Bourke, Joanna (2007), Rape: Sex, Violence, History. Berkeley: Counterpoint.

Broadbent, Lucy (2011) "Rape in the US Military: America's Dirty Little Secret. A Female Soldier in Iraq Is more likely to Be Attacked by a Fellow Soldier than Killed by Enemy Fire”. Consultado a 20.10.2014, em https://www.theguardian.com/ society/2011/dec/09/rape-us-military.

Brownmiller, Susan (1975), Against Our Will: Men, Women, and Rape. New York: Simon \& Schuster.

Bumiller, Kristin (2008), In an Abusive State. How Neoliberalism Appropriated the Feminist Movement against Sexual Violence. Durham/London: Duke University Press.

Carreiras, Helena (2010), "Gendered Culture in Peacekeeping Operations", International Peacekeeping, 17(4), 471-485. DOI: 10.1080/13533312.2010.516655.

Chan, Stephen (2011), "On the Uselessness of New Wars Theory: Lessons from African Contexts”, in Christine Sylvester (org.), Experiencing War. New York: Routledge, 79-93.

Chiwengo, Ngwarsungu (2008), "When Wounds and Corpses Fail to Speak: Narratives of Violence and Rape in Congo (DRC)", Comparative Studies of South Asia, Africa and the Middle East, 28(1), 78-92. DOI: 10.1215/1089201x-2007-057.

Collier, Paul; Hoeffler, Anke (1998), "On Economic Causes of Civil War", Oxford Economic Papers, 50(4), 563-573. DOI: 10.1093/oep/50.4.563.

Collier, Paul; Hoeffler, Anke (2004), "Greed and Grievance in Civil War", Oxford Economic Papers, 56(4), 563-595. DOI: 10.1093/oep/gpf064.

Cohen, Dara Kay (2013), "Explaining Rape during Civil War: Cross-National Evidence (1980-2009)", American Political Science Review, 107(3), 461-477. DOI: 10.1017/ S0003055413000221. 
Cohn, Carol; Kinsella, Helen; Gibbings, Sheri (2004), "Women, Peace and Security: Resolution 1325”, International Feminist Journal of Politics, 6(1), 130-140. DOI: 10.1080/1461674032000165969.

CSNU - Conselho de Segurança das Nações Unidas (2000), Resolution 1325 (2000). Adopted by the Security Council at Its 4213th Meeting, on 31 October 2000, UN Doc. S/RES/1325 (2000). Consultado a 15.03.2018, em http://undocs.org/en/S/ RES/1325(2000).

CSNU - Conselho de Segurança das Nações Unidas (2008), Resolution 1820 (2008). Adopted by the Security Council at Its 5916th Meeting, on 19 June 2008, UN Doc. S/RES/1820 (2008). Consultado a 15.03.2018, em http://undocs.org/en/S/ RES/1820(2008).

CSNU - Conselho de Segurança das Nações Unidas (2009), Resolution 1888 (2009). Adopted by the Security Council at Its 6195th Meeting, on 30 September 2009, UN Doc S/RES/1888 (2009). Consultado a 15.03.2018, em http://undocs.org/en/S/ RES/1888(2009).

CSNU - Conselho de Segurança das Nações Unidas (2010), Resolution 1960 (2010). Adopted by the Security Council at Its 6453rd Meeting, on 16 December 2010, UN Doc. S/RES/1960 (2010). Consultado a 15.03.2018, http://undocs.org/en/S/ RES/1960(2010).

CSNU - Conselho de Segurança das Nações Unidas (2013), Resolution 2106 (2013). Adopted by the Security Council at Its 6984th Meeting, on 24 June 2013, UN Doc S/RES/2106 (2013). Consultado a 15.03.2018, em http://undocs.org/en/S/ RES/2106(2013).

Das, Veena; Kleinman, Arthur (2000), “Introduction”, in Veena Das; Arthur Kleinman; Mamphela Raphele; Pamela Reynolds (orgs.), Violence and Subjectivity. Berkeley/ /Los Angeles/London: University of California Press, 1-18.

Davis, Angela (1983), "Rape, Racism and the Myth of the Black Rapist", Women, Race \& Class. New York: Vintage, 172-201.

Davies, Sara E.; True, Jacqui (2015), "Reframing Conflict-Related Sexual and Gender-Based Violence: Bringing Gender Analysis Back in”, Security Dialogue, 46(6), 495-512. DOI: 10.1177/0967010615601389.

Defeis, Elizabeth (2008), "U.N. Peacekeepers and Sexual Abuse and Exploitation: An End to Impunity”, Washington University Global Studies Law Review, 7(2), 185-214.

Duffield, Mark (2001), Global Governance and the New Wars: The Merging of Development and Security. London/New York: Zed Books.

Duffield, Mark (2010), "Risk-Management and the Fortified Aid Compound: Everyday Life in Post-Interventionary Society”, Journal of Intervention and Statebuilding, 4(4), 453-474. DOI: 10.1080/17502971003700993.

Duffield, Mark; Waddell, Nicholas (2006), "Securing Humans in a Dangerous World", International Politics, 43(1), 1-23. DOI: 10.1057/palgrave.ip.8800129. 
Elshtain, Jean Bethke (1987), Women and War. New York: Basic Books.

Enloe, Cynthia (1989), Bananas, Beaches, Bases: Making Feminist Sense of International Politics. Berkeley/Los Angeles/London: University of California Press.

Enloe, Cynthia (1993), The Morning After: Sexual Politics at the End of the Cold War. Berkeley/Los Angeles/London: University of California Press.

Enloe, Cynthia (2000), Maneuvers: The International Politics of Militarizing Women's Lives. Berkeley: University of California Press.

Eriksson Baaz, Maria; Stern, Maria (2009), "Why Do Soldiers Rape? Masculinity, Violence, and Sexuality in the Armed Forces in the Congo (DRC)", International Studies Quarterly, 53(2), 495-518. DOI: 10.1111/j.1468-2478.2009.00543.x.

Eriksson Baaz, Maria; Stern, Maria (2013), Sexual Violence as a Weapon of War? Perceptions, Prescriptions, Problems in the Congo and Beyond. New York: Zed Books. Ferguson, James (1990), The Anti-Politics Machine: "Development", Depoliticization, and Bureaucratic Power in Lesotho. Cambridge: Cambridge University Press.

Garraio, Júlia (2012), “'Arresting Gaddafi Will Be the most Effective Way to Stop these Rapes'. Sexual Violence in the Western Media's Coverage of the War in Libya”, e-cadernos CES, 16, 111-142. Consultado a 10.03.2018, em http://journals.openedition. org/eces/1037. DOI: 10.4000/eces.1037.

Garraio, Júlia (2013), "Hordes of Rapists: The Instrumentalization of Sexual Violence in German Cold War Anti-Communist Discourses”, RCCS Annual Review, 5, 46-63. DOI: $10.4000 /$ rccsar.476.

Hansen, Lene (2001), "Gender, Nation, Rape. Bosnia and the Construction of Security”, International Feminist Journal of Politics, 3(1), 55-75. DOI: 10.1080/ 14616740010019848.

Hansen, Lene (2012), "Reconstructing Desecuritisation: The Normative-Political in the Copenhagen School and Directions for how to Apply It", Review of International Studies, 38(3), 525-546. DOI: 10.1017/S0260210511000581.

Harrington, Carol (2010), Politicization of Sexual Violence from Abolitionism to Peacekeeping. Farnham, United Kingdom: Ashgate Publishing Ltd [e-book].

Hirschauer, Sabine (2014), The Securitization of Rape Women, War and Sexual Violence. New York: Palgrave Macmillan.

Hutchings, Kimberly (2008), "Making Sense of Masculinity and War", Men and Masculinities, 10(4), 389-404. DOI: 10.1177/1097184X07306740.

Jabri, Vivienne (2007), War and the Transformation of Global Politics. New York: Palgrave Macmilan.

Jabri, Vivienne (2013), "Peacebuilding, the Local and the International: A Colonial or a Postcolonial Rationality?”, Peacebuilding, 1(1), 3-16. DOI: 10.1080/21647259. 2013.756253.

Kaldor, Mary (2001), New \& Old Wars. Organized Violence in a Global Era. Stanford: Stanford University Press [reimpr.; orig. 1999]. 
Kalyvas, Stathis N. (2001), “'New' and 'Old' Civil Wars: A Valid Distinction?”, World Politics, 54(1), 99-118. DOI: 10.1353/wp.2001.0022.

Kimmel, Michael (2005), "Masculinity and Gun Violence: The Personal Meets the Political”. Comunicação apresentada no seminário "Men, Women and Gun Violence: Options for Action”, UN Second Biennial Meeting of States, 14 de julho, New York, United States of America.

Laclau, Ernesto; Mouffe, Chantal (1985), Hegemony and Socialist Strategy. Towards a Radical Democratic Politics. London: Verso.

Leatherman, Janie (2011), Sexual Violence and Armed Conflict. Cambridge: Polity Press. Lecaplain, Guillaume; Moran, Anaïs (2018), "Lycée Saint-Cyr: une machine à broyer les femmes”, Libération, 22 de março. Consultado a 23.03.2018, em http://www. liberation.fr/france/2018/03/22/lycee-saint-cyr-une-machine-a-broyer-les-femmes_ 1638211.

Mackenzie, Megan (2010), “Securitizing Sex?”, International Feminist Journal of Politics, 12(2), 202-221. DOI: 10.1080/14616741003665250.

Mackinnon, Catherine (1994), “Rape, Genocide, and Women's Human Rights”, Harvard Women's Law Journal, 17, 5-16.

Meger, Sarah (2016), "The Fetishization of Sexual Violence in International Security”, International Studies Quarterly, 60(1), 149-159. DOI: 10.1093/isq/sqw003.

Moura; Tatiana (2010), Novíssimas guerras. Espaços, identidades e espirais de violência. Coimbra: CES/Almedina.

Müller, Martin (2008), "Reconsidering the Concept of Discourse for the Field of Critical Geopolitics: Towards Discourse as Language and Practice", Political Geography, 27(3), 322-338. DOI: 10.1016/j.polgeo.2007.12.003.

Munn, Jamie (2008), “The Hegemonic Male and Kosovar Nationalism, 2000-2005”, Men and Masculinities, 10(4), 440-456. DOI: 10.1177/1097184X07306744.

Nayak, Meghana; Suchland, Jennifer (2006), "Gender Violence and Hegemonic Projects”, International Feminist Journal of Politics, 8(4), 467-485. DOI: 10.1080/ 14616740600945024.

Nusair, Isis (2008), "Gendered, Racialized, and Sexualized Torture at Abu Ghraib”, in Robin Riley; Chandra Talpade Mohanty; Minnie Bruce Pratt (orgs.), Feminism and War. Confronting US Imperialism. London/New York: Zed Books, 179-193.

Oprea, Anastasia Maria (2013), Gender, Sexual Violence and Securitization in Two (Western) Media Discourses on DRC. Dissertação de Mestrado em Estudos Africanos apresentada no ISCTE - Instituto Universitário de Lisboa, Lisboa, Portugal.

Pankhurst, Donna (2010), "Sexual Violence in War”, in Laura Shepherd (org.), Gender Matters in Global Politics. A Feminist Introduction to International Relations. London/ /New York: Routledge, 159-170.

Pratt, Nicole (2013), "Reconceptualizing Gender, Reinscribing Racial-Sexual Boundaries in International Security: The Case of UN Security Council Resolution 1325 on 
'Women, Peace and Security'”, International Studies Quarterly, 57(4), 772-783. DOI: 10.1111 isqu. 12032.

Pureza, José Manuel (2013), “A turbulência das zonas de fronteira: estereótipos, representações e violências reais”, in António Sousa Ribeiro (org.), Representações da violência. Coimbra: CES/Almedina, 201-211.

Roque, Sílvia (2012), "Lógicas de guerra e a reprodução das margens: gangues, mulheres e violência sexuada em El Salvador", Revista Crítica de Ciências Sociais, 96, 87-116. DOI: $10.4000 /$ rccs.4830.

Santos, Rita (2018), “Agenda mulheres, paz e segurança”. Módulo 3 do curso sobre planos de ação nacionais para a implementação da Resolução do Conselho de Segurança da ONU 1325, 10 a 14 de abril. Coimbra: Akto - Direitos Humanos e Democracia.

Santos, Rita; Roque, Sílvia; Moura, Tatiana (2012), "Conexões perdidas: representações de género, violência (armada) e segurança na Resolução 1325”, Revista Crítica de Ciências Sociais, 96, 165-196. DOI: 10.4000/rccs.4867.

Scheper-Hughes, Nancy; Bourgois, Philippe (2004), "Introduction: Making Sense of Violence", in Nancy Scheper-Hughes; Philippe Bourgois (orgs.), Violence in War and Peace: An Anthology. Oxford: Blackwell Publishing, 1-27.

Shepherd, Laura (2007), “'Victims, Perpetrators and Actors' Revisited: Exploring the Potential for a Feminist Reconceptualisation of (International) Security and (Gender) Violence", BJPIR - British Journal of Politics and International Relations, 9(2), 239-256. DOI: 10.1111/j.1467-856x.2007.00281.x.

Shepherd, Laura (2008), "Power and Authority in the Production of United Nations Security Council Resolution 1325”, International Studies Quarterly, 52(2), 383-404. DOI: 10.1111/j.1468-2478.2008.00506.x.

Shepherd, Laura (2011), "Sex, Security and Superhero(in)es: From 1325 to 1820 and Beyond", International Feminist Journal of Politics, 13(4), 504-521. DOI: 10.1080/14616742.2011.611659.

Simi , Olivera (2010), "Does the Presence of Women Really Matter? Towards Combating Male Sexual Violence in Peacekeeping Operations”, International Peacekeeping, 17(2), 188-199. DOI: 10.1080/13533311003625084.

Via, Sandra (2010), "Gender, Militarism, and Globalization: Soldiers for Hire and Hegemonic Masculinity”, in Laura Sjoberg; Sandra Via (orgs.), Gender, War, and Militarism: Feminist Perspectives. Santa Barbara/Denver/Oxford: Praguer, $42-56$.

Waever, Ole (1995), "Securitisation and De-Securitisation”, in Ronnie Lipschutz (org.), On Security. New York: Columbia, 46-87.

Whitworth, Sandra (2005), "Militarized Masculinities and the Politics of Peacekeeping: The Canadian Case", in Ken Booth (org.), Critical Security Studies in World Politics. Boulder, CO: Lynne Rienner Publishers, 89-106. 
Wood, Elisabeth Jean (2014), "Conflict-Related Sexual Violence and the Policy Implications of Recent Research”, International Review of the Red Cross, 96(894), 457-478. DOI: 10.1017/S1816383115000077.

Zipfel, Gaby (2013), “'Let Us Have a Little Fun’: The Relationship between Gender, Violence and Sexuality in Armed Conflict Situations”, RCCS Annual Review, 5, 32-45. DOI: $10.4000 /$ rccsar.469.

\author{
Sílvia Roque \\ Centro de Estudos Sociais da Universidade de Coimbra \\ Colégio de S. Jerónimo, Largo D. Dinis, Apartado 3087, 3000-995 Coimbra, Portugal \\ Contacto: silviar@ces.uc.pt
}

\section{Sexual Violence and International Security: Depoliticization, De-contextualization and Colonization of an Agenda}

This article analyses the United Nations Security Council Resolutions on sexual violence in contexts of armed conflict. It understands these resolutions as a securitization process through which sexual violence becomes punishable, preventable and something to be fought against in the international realm. The article argues that by circumscribing sexual violence to the security paradigm, these Resolutions end up nevertheless undermining the understanding of sexual violence as a broader socio-political issue, anchored in gender representations and ideologies and related to dynamics of power and violence on a global scale, compromising its emancipatory potential.

Keywords: feminism; genre; security; sexual violence; United Nations Security Council.

\section{Violence sexuelle et sécurité internationale: dépolitisation, décontextualisation et colonisation d'un agenda}

Cet article se penche sur les Résolutions du Conseil de Sécurité des Nations Unies portant sur la violence sexuelle dans des contextes de conflit armé comme un moment de sécurisation à partir duquel la violence sexuelle est perçue comme un acte passible de punition, de combat et de prévention dans la sphère internationale. Nous soutenons que, en limitant la violence sexuelle au paradigme de la sécurité, les Résolutions finissent toutefois par mettre en cause l'entendement de celle-ci comme une question sociopolitique plus vaste, ancrée dans des représentations et des idéologies de genre et en rapport direct avec la dynamique de pouvoir et de violence à l'échelle globale, mettant ainsi en cause son potentiel émancipateur.

Mots-clés: Conseil de Sécurité des Nations Unies; féminisme; genre; sécurité; violence sexuelle. 